\title{
¿EN LOS UMBRALES DEL GÉNERO? BEAUVOIR, BUTLER Y EL FEMINISMO ILUSTRADO ${ }^{1}$
}

\author{
LETICIA SABSAY \\ Universitat de València - Universidad de Buenos Aires
}

Recibido: 09/01/2010

Aceptado: 20/04/2010

\section{Resumen}

En este trabajo me propongo analizar ciertas derivas de la categoría de género, nodal al proyecto feminista ilustrado, con el fin de señalar algunos de los actuales desafíos que se le plantean. Para ello, me centraré en la lectura que Judith Butler hace de Simone de Beauvoir, referente indiscutible de esta corriente, para pasar luego a la crítica que se le ha hecho a la perspectiva de la performatividad genérica, entendiendo que la cuestión de «cómo se deviene mujer» perfila el meollo de esta polémica. En este contexto, me detendré en el debate en torno del constructivismo radical que parecería tener origen en el postestructuralismo, intentando revisar el carácter también constructivista que podría observar la noción de género derivada de las apreciaciones de Beauvoir, atendiendo a la tensión que esta tradición plantea frente a la de diferencia sexual.

Palabras clave: género, diferencia sexual, constructivismo, performatividad, Cuerpo.

\begin{abstract}
The aim of this paper is to analyze certain aspects of the category of gender, which is central to the enlightened feminist project, in order to show some of the challenges to which this project is currently confronted. For doing so, I will take Judith Butler's reading of Simone de Beauvoir -an indisputable referent for such feminist frame- and the contesting arguments made against the performativity of gender by this tradition. My contention is that the question around «how to become a woman» continues to

1. Una primera versión de este artículo fue expuesta a modo de ponencia con el título «¿En los umbrales del género? Beauvoir, Butler y las derivas de la lectura», en el Seminario «Simone De Beauvoir: un siglo de feminismo», Institut Universitari d'Estudis de la Dona, Universitat de Valencia, Valencia, 28 de mayo de 2009.
\end{abstract}


be at the center of this debate. Therefore, in light of the tension between Beauvoir's equality tradition and the problem of sexual difference, I will focus on the debate concerning post-estructuralist radical constructivist views and their relation to Beauvoir's own constructivism.

Keywords: gender, sexual difference, constructivism, Performativity, Body. 
La dicotomía entre el feminismo de la igualdad y el feminismo de la diferencia señala una formación espacio-temporal concreta entre las múltiples historias feministas, proporcionándonos un particular esquema interpretativo mediante el cual «leer» una cierta relación entre los diferentes saberes, prácticas y debates que han venido delineando el campo del feminismo. Si bien esta clasificación a través de la cual se han homogeneizado y polarizado estas dos corrientes no ha sido ni es la única que, desde luego, ha servido a la organización de la historiografía feminista - de hecho, dada su trayectoria biográficointelectual y su contexto, muchas de las autoras que sirven de referentes a estas corrientes no reconocerían con tanta claridad esta terminante clasificación-, su relevancia historiográfica es, sin embargo, indiscutible. Ciertamente, en ella podemos reconocer la tensión fundamental entre dos constructos nodales a la tradición feminista: la travesía del feminismo perfilada dentro de este marco nos permite recorrer las distintas conceptualizaciones del género, siempre en tensión con la perspectiva feminista basada en la noción de diferencia sexual, hasta la crisis que el postestructuralismo supondría para el par diferencia/igualdad.

En efecto, las derivas de la categoría de género se encuentran en el centro de estos debates y, de hecho, el género ha sido la categoría distintiva en torno de la cual se configura el proyecto feminista por la igualdad. En este contexto, entonces, mi interés en este trabajo será el de analizar los actuales problemas que se le plantean a esta categoría. Prestando especial atención a su problemático vínculo con la noción de diferencia. Para ello, me centraré en la lectura que Judith Butler hace de Simone de Beauvoir, referente indiscutible de esta corriente, y en las críticas que desde el feminismo ilustrado se le han hecho a la perspectiva de la performatividad genérica, ya que entiendo que la cuestión de «cómo se deviene mujer» perfila el meollo de esta polémica.

\section{El 'devenir mujer' y la desigualdad genérica}

De Simone de Beauvoir a Judith Butler: en este sintagma podría resumirse, de algún modo, la travesía desde el feminismo a la teoría queer; o si se quiere, la historia reciente del feminismo a secas. Si entendemos que esta reciente 
historia ha estado signada por la categoría de género, ciertamente, como en una especie de temporalidad contaminada, difusa, en una primera imagen parecería como si de algún modo Beauvoir se situara en la antesala del género, antes de la categoría pero a la vez ya en ella, mientras que Butler, atravesada por esta categoría, desde las mismas entrañas del género pareciera estar saliéndose de él todo el tiempo, intentando ir por delante de ella.

En efecto, podría postularse que en el tránsito desde la pregunta por cómo se llega a devenir «mujer» en el caso de Beauvoir hasta la pregunta por cómo se llega a ser a través del género, o por decirlo de otro modo, cómo se deviene sujeto y por tanto sujeto generizado, en el caso de Butler, se aloja la historia de la categoría de género, desde su prometedor surgimiento hasta la actual crisis del género en tanto categoría crítica.

Esta categoría aún por nacer, y que Beauvoir no utilizaría todavía, encontró en aquella obra seminal, El segundo Sexo, sus fundamentos. Como sabemos, «aquel llegar a ser» de la mujer, que ponía de manifiesto que la biología no era un destino, dio lugar a la comprensión de que del sexo femenino al «ser mujer» había una gran distancia, y que esta distancia era la de la praxis humana: si, de acuerdo con Beauvoir, hemos de conceder que en la naturaleza podríamos llegar a encontrar algo así como «hembras», es indudable que en cualquier caso «ser mujeres» se plantea a partir de su mirada como un fenómeno propio de la humanidad, entendida la humanidad como una realidad histórica. Escribía Beauvoir en aquel momento:

La humanidad no es una especie animal: es una realidad histórica... De esta forma, no se puede considerar a la mujer como un organismo sexuado: entre las circunstancias biológicas, sólo tienen importancia las que adoptan un valor concreto en la acción; la conciencia que tiene la mujer de ella misma no está definida únicamente por su sexualidad ${ }^{2}$.

De este modo, se abría el lugar para el nacimiento del género como un concepto que intentaba señalar precisamente este carácter social, histórico, de la diferencia sexual. Ahora bien, pensando en esta impronta, resulta que, en realidad, a partir de aquí se plantean, entre tantas otras, al menos dos lecturas posibles: en primer lugar, aquella que centrará su preocupación en el objetivo de la igualdad; en segundo término, aquella que pondrá el acento en la historicidad propia de la generización.

La primera lectura, en la vertiente de la tradición ilustrada, retomará el carácter socialmente configurado de las relaciones entre los sexos, poniendo de relieve la necesidad indisputable de cualquier proyecto feminista de luchar

2. BeAuvoir, Simone de. El segundo sexo. Madrid, Cátedra, 2005 [1949], p. 115. 
contra la desigualdad genérica. Lo que desde esta visión no será natural, y por tanto, lo que no se podrá justificar a través de ningún argumento esencialista, es que la diferencia sexual se convierta en desigualdad genérica, o puesto en otros términos, que la desigualdad genérica pueda encontrar alguna justificación en el hecho «biológico» de la diferencia de sexos. De este modo, lo que en esta lectura se retoma del planteamiento de Beauvoir es fundamentalmente el acento en el carácter histórico del hecho de que las mujeres, o todavía en ese momento «la mujer», se configuren como la Alteridad, la Otra. Como plantea Beauvoir:

Negarse a ser Alteridad, rechazar la complicidad con el hombre sería para ellas renunciar a todas las ventajas que les puede procurar la alianza con la casta superior... además del riesgo económico evita el riesgo metafísico de una libertad que debe inventar sus propios fines sin ayuda... De esta forma la mujer no se reivindica como sujeto, porque carece de los medios concretos para hacerlo... ${ }^{3}$

Esto es lo que se retoma dentro de esta lectura: el hecho de que el devenir genérico de las mujeres suponga para éstas quedar en una situación de subordinación. Y dado que para Beauvoir, signada por la impronta existencialista, la posibilidad de devenir sujeto estará dada por la capacidad de trascender la inmanencia de la propia situación, en términos más beauvoirianos, lo que se cuestionará es el hecho de que las mujeres estén condenadas a la inmanencia de su fisicalidad o, en todo caso, a una trascendencia que de todos modos será engañosa, pues la auto-afirmación de las mujeres como sujetos humanos y por tanto libres se verá, bajo estas condiciones, expuesta al castigo o restringida por unas condiciones de opresión que en realidad limitan su libertad.

En síntesis, en esta primer lectura lo que se pone de relieve no es tanto el problema de la generización en sí, sino más bien el de la desigualdad que ésta implica. A partir de aquí, se insistirá en el carácter arbitrario e injusto de la desigualdad social que implica devenir mujer, pero no se cuestionará el carácter también social y por tanto arbitrario de ese hecho social que implica ya el devenir mujer en sí mismo. En otras palabras, el género entendido como una categoría que designa la desigualdad social entre los sexos, parecería dejar a un lado la pregunta por cómo se configuran estos últimos. Siguiendo a Butler, diríamos que es justamente esta lectura de Beauvoir la que da lugar a una concepción del género como la «interpretación cultural del sexo», la cual, en efecto, deriva al género de una diferencia sexual que permanece sin ser cuestionada.

3. Ibíd.., p. 55.

Feminismo/s 15, junio 2010, pp. 119-135 
Esta es una de las críticas más importantes que Butler realiza a esta concepción culturalista del género en el libro que abriera una de las polémicas más salientes dentro del feminismo contemporáneo, El género en disputa. Allí, la autora señala que si se entiende al género como una categoría estrictamente socio-cultural, o bien éste se independiza absolutamente del sexo, con lo cual el sexo deja de tener relevancia alguna para considerar quién es una mujer, o bien se deriva directamente del sexo, y queda adosado a él $1^{4}$. Si se presupone la alineación sexo-género, resulta que la diferencia sexual persiste en el centro del género como su substrato -mudo, oculto, y aun repudiado-, y que, paradójicamente, es esta tajante división entre sexo biológico y género cultural, la que los mantiene unidos, habilitando consecuentemente a la pervivencia de su concepción binaria. Desde la concepción de Butler, por el contrario, esta partición binaria, así como la división entre naturaleza y cultura que está a la base de la misma, es ya una operación socio-cultural ${ }^{5}$.

Mi impresión es que es precisamente porque el género puede concebirse binariamente gracias al implícito no cuestionamiento de la diferencia sexual, que cierto feminismo vio entonces, amenazados su tarea política y su sentido, cuando desde la epistemología feminista antiesencialista y postestructuralista se emprendió la crítica a este binarismo, tanto genérico como sexual. Es a partir de aquí que puede comprenderse la fantasía de que la puesta en crisis del binarismo del género ponía en peligro a la misma categoría de género en sí. ¿Puede el género concebirse por fuera de su estructuración binaria? ¿Qué implica pensar al género como un eje a través del que se materializa el poder posicionando a los individuos diferencialmente de acuerdo a su identificación genérica -o más bien, identificando a los individuos como genéricamente diferenciados-, sin presuponer que esta generización habrá de culminar necesariamente en dos opciones? Decir, por ejemplo, que es la misma normativa heterocentrada del género, o el género en tanto normativa, el que establece las restrictivas opciones «mujer»/«varón», o criticar además la presunción de que estas identificaciones excluyentes -mujer/varón- corresponderán necesariamente a cierto tipo de cuerpos en un caso y otro, ¿implica acaso disolver el género?

4. Desarrollo esta cuestión en Los dilemas del antiesencialismo en la teoría feminista contemporánea: una reflexión en torno a Judith Butler, Almería, Instituto de Estudios Almerienses/Diputación de Almería, 2007.

5. En este sentido, cabe remarcar que por el mismo motivo, Butler cuestionará radicalmente las nociones tanto naturalista como psicoanalítica de la diferencia sexual en tanto distinción simbólica, como una instancia distinta de las operaciones del poder social. 


\section{La crítica a la normativa binaria del género}

Comencé este ensayo planteando que entre Beauvoir y Butler se podía leer una cierta historia de esta categoría... Deshacer el género, Undoing Gender, ésta es la última obra que Butler publicara específicamente sobre el género. Esta compilación de artículos realizada en el 2004 lleva un título por demás sugerente. ¿Se trata allí efectivamente de «deshacer al género»? Las resonancias del vocablo «deshacer» nos llevan en el castellano a la idea de disolver, aniquilar, cancelar. Deshacer el género evocaría desde este punto de vista de la traducción, en efecto: el fin del género. Pero en inglés, el término «undo» evoca además de la cancelación, otros horizontes de sentido: el de descubrir, develar, el de aflojar -como cuando aflojamos un nudo-; y también el de cambiar, modificar, o el de alterar, desestructurar, desarmar (como cuando decimos de una emoción que nos embarga profundamente, que nos hace «sentir desarmadas»).

En este sentido, me parece que más que apuntar al fin del género, esta idea de «undoing gender» señala la necesidad de cuestionar sus normas, y en este contexto su binariedad: desarmar la normativa del género no implicaría, en esta clave, terminar con el género, sino más bien cuestionar su carácter normativo, exponerlo en su ser excluyente, comprender que el proceso de generización es en sí mismo violento y supone una cantidad de restricciones, prohibiciones y sanciones en función de unos ideales o normas cuyo horizonte parecería seguir estando definido por la diferencia sexual.

Esta última interpretación es la que nos lleva a plantear la segunda lectura que podía hacerse de Beauvoir a la que se hacía referencia al comienzo: en este segundo caso se insistirá en el germen que puede encontrarse en Simone de Beauvoir para una deconstrucción radical del género. Esta es, efectivamente, la idea que encontramos en Butler. La pregunta que se plantea esta autora al comienzo de «Variaciones sobre sexo y género: Beauvoir, Wittig y Foucault» ${ }^{6}$ es precisamente qué implicancias tiene esta idea de que «no se nace mujer, se llega a serlo»y, para desarrollar su argumento, Butler analiza las diferentes aristas que reviste la concepción del género o de la generización (o el devenir mujer) bien como proyecto o como aprendizaje obligado en relación con el cuerpo sexuado.

De acuerdo con su planteo, si el género es concebido como un proyecto, el género se convierte en algo escindido de lo corporal. Abriendo la posibilidad

6. BUtLER, Judith. «Variaciones sobre sexo y género: Beauvoir, Wittig y Foucault». En S. Benhabib y D. Cornell (eds.), Teoría feminista/Teoría crítica. Valencia, Alfons el Magnànim, 1989, pp. 193-211. 
de un espacio de trascendencia y por tanto de libertad, se nos daría como una elección en función de una situación, y se convertiría en la vía para acceder a la libertad como trascendencia del cuerpo. Como aprendizaje obligado, el género sería comprendido, en cambio, como condicionamiento social que obliga compulsivamente a los individuos a generizarse de cierto modo. En este último caso, el género no sería sino un conjunto de normas culturales que nos preceden y que marcan los parámetros a través de los cuales aprendemos a vivir nuestro cuerpo. La paradoja que plantea Butler en aquel artículo es la siguiente:

[El] género se convierte en el locus corpóreo de significados culturales tanto recibidos como innovados. Y en este contexto la «elección» pasa a significar un proceso corpóreo de interpretación dentro de una red de normas culturales profundamente establecidas.

Cuando se concibe el cuerpo como un locus cultural de significados de género, deja de estar claro qué aspectos de este cuerpo son naturales o cuáles carecen de impronta cultural. Desde luego, ¿cómo vamos a encontrar el cuerpo que preexiste a su interpretación cultural? Si el género es la corporeización de la elección, y la enculturación de lo corpóreo, ¿qué le queda entonces a la naturaleza, y en qué se ha convertido el sexo?

Volveré a las especulaciones de Butler sobre esta tensión entre el proyecto -donde parece tener cierto peso un sujeto soberano y volitivo- y el condicionamiento social, pero antes quisiera insistir en el hecho de que en esta lectura de Butler es ya el género en sí mismo y no estrictamente la desigualdad genérica entre varones y mujeres, el que se pone en cuestión. Ahora bien, planteada así, la observación es engañosa puesto que no es «el género» a secas lo que en el texto de Butler se cuestiona en realidad, sino la concepción del género como un constructo cultural mediante el cual se interpretaría un sexo (independiente del género) que una ya «naturalmente» se supone que es.

Planteado de este modo, antes que restringir y desacreditar la categoría de género, lo que parecería plantear Butler es, al contrario, una aguda reformulación de la categoría: de hecho lo que se deja leer en esta cita y lo que, a mi entender, plantea Butler en sus primeras obras (sobre todo en El género en disputa y en Cuerpos que importan) es una aguda generización del sexo, lo que implica extender la categoría de género a un objeto teórico de crucial importancia para entender la lógica genérica, a saber el cuerpo sexuado.

Es aquí donde las críticas de Butler no sólo impugnan una concepción naturalizada del sexo, sino que se extienden al feminismo postestructuralista de la diferencia sexual. Desde su punto de vista la idea de que la «otredad»

7. Ibíd., p. 194.

Feminismo/s 15, junio 2010, pp. 119-135 
radical de la mujer con respecto al falogocentrismo se base en una distinción simbólica anterior a todo orden cultural -ya sea en la versión hegeliana de Luce Irigaray, o en la oposición entre los órdenes simbólico y semiótico de Julia Kristeva-, trascendentaliza una realidad genérica propia de la matriz heterosexual que, puesto en términos lacanianos, reduce la economía sexual a sólo dos posiciones sexuadas posibles en base a la complementariedad y la exclusión. Contra la consideración de que las posiciones masculina -tener el falo-y femenina -ser el falo- son las únicas primarias, naturales y originarias, a partir de lo cual, todas las otras posiciones minoritarias sólo podrán gozar de una posición secundaria y derivada de aquellas, Butler impugna el carácter previo al orden de las significaciones culturales de la diferencia sexual.

Esta generización del sexo que fue muchas veces leída en clave de «culturalización» del cuerpo fue de hecho muy criticada y bastante mal recibida por los diversos feminismos. Si bien estas observaciones podían ser leídas como una radicalización de la teoría de género, mostrando cómo ya en la sexualización de los cuerpos operaba la opresión del género, en la medida en que Butler le arrebataba al cuerpo la propiedad inmutable y trascendental de su sexo, el feminismo vio tambalear la seguridad ontológica de que más allá de toda configuración cultural, la mujer, en tanto variante de la especie humana, simple y ostensiblemente es. Quizás sea debido a esta radical deconstrucción del género, que supone quitarle al género su base sexual en tanto que componente inmutable, lo que a su vez implicaba cuestionar su organización binaria, que la recepción de la teoría de la performatividad del género de Butler haya resultado tan polémica. Y tal vez, la polémica tenga su razón de ser. Sería obtuso al fin y al cabo desmerecer la propia historicidad del feminismo, sus dificultades y sus debates. Al fin de cuentas, quizás haya algo de cierto en que Butler ha deshecho al género, pero este enunciado sólo tiene sentido si concebimos la categoría de género como expresión de una diferencia sexual previa al orden socio-cultural y por tanto exenta de la matriz de las relaciones de poder.

De lo que se trata en el proyecto performativo, por el contrario, es de reconsiderar el género como una normativa. Este desplazamiento conceptual implica, desde luego, concebir el género no como la característica de un sujeto, sino como una práctica y una relación social, algo que, por otra parte, ya estaba presente de forma saliente en la clásica formulación de Joan W. Scott ${ }^{8}$. Esto supone decir otra cosa sobre el género, ya que en este caso, el género

8. SCOTT, Joan W. «El género, una categoría útil para el análisis histórico». En C. Stimpson, y M. Navarro (eds.), Sexualidad, género y roles sexuales. Buenos Aires, FCE, 1999. 
no circunscribiría meramente el conjunto de normas que harían a los roles, expectativas, etc., sino a la norma que, como plantearía Butler, demarca los límites de inteligibilidad de lo que concebimos como sexualidad y humanidad. Una cosa es ver el género como un atributo de las personas, o como un conjunto de rasgos culturales de las personas, y otra muy distinta ver el género como un dispositivo normativo que funciona como una matriz de producción de subjetividad.

En este sentido, decir que el género es performativo o que el género se configura performativamente es tramposo, pues no hay un género que estuviese allí previo a su actualización performativa, y donde lo performativo se daría como un atributo o predicado del género. Al decir que el género es performativo, lo que estamos planteando es que estrictamente hablando el género no existe sino como la fijación de un proceso incesante de generización, entendida ésta como una matriz productora de subjetividad que, a la luz de Deshacer el género, entenderíamos como una matriz que, de acuerdo al eje diferenciador "género» (que, de todos modos, nunca aparece de forma pura y aislada), opera exclusiones mediante las que se configura la inteligibilidad de los sujetos y consecuentemente, distribuye diferencialmente el reconocimiento y la vulnerabilidad.

Si entendemos al género como una normativa, es decir como un dispositivo de producción de formaciones subjetivas, se hace claro que la crítica de las relaciones de poder que inscribe el género, un objetivo que hace a los ideales feministas, supondría para el feminismo comprometerse con la crítica de la generización misma, y consecuentemente, comprometerse entonces con la desarticulación de esta normativa no sólo en lo que las exclusiones y sanciones que ésta supone para las mujeres, sino para otros colectivos codificados hoy como «minorías sexuales». Esta es la línea que ha seguido el feminismo queer.

\section{En torno del constructivismo pre y post-estructuralista}

En paralelo, precisamente porque ésta implica problematizar el proceso de generización mismo, la redefinición performativa del género ha sido profusamente cuestionada. Ahora bien, de las muchas críticas que se le han dedicado, en este marco quiero llamar la atención sobre dos tendencias. Por un lado, se ha afirmado que la conceptualización de un sujeto performativo implicaba un «agente capaz de manipular o elegir su identidad de género». Sintomáticamente, en esta línea la interpretación de la performatividad genérica fue desestimada porque supuestamente reponía un sujeto libre y soberano de 
voluntad y conciencia, capaz de moldear estratégica e instrumentalmente la posición de género a asumir.

Si el género ya no dependiese del cuerpo, se afirma en esta clave, éste quedaría librado a la voluntad o la elección. Si el género no es más que la actuación de sí mismo, y no hay nada anterior al género -ni psiquis, ni interioridad de la conciencia, ni sexo- que el género venga a expresar, entonces el género quedaría librado a la voluntad del actor social. Esta línea argumental es la que nos enseña, por ejemplo, Teresa López Pardina en el prólogo que hace a la edición en español de $E l$ segundo sexo ${ }^{9}$. Haciendo un riguroso y extenso recorrido de las interpretaciones que se han hecho de Beauvoir, López Pardina critica a Butler por cuanto al romper la binariedad del género, ésta estaría siendo infiel al planteamiento de Beauvoir. La autora afirma:

Si el género es construcción cultural y también elección, Butler se congratula de que una ya pueda elegir el género, puesto que no tiene por qué estar vinculado al sexo y además tampoco tiene por qué atenerse a una clasificación binaria -masculino o femenino-; podríamos «inventar» otros géneros... distinguirnos no por criterios binarios sino múltiples, con lo que conseguiríamos una proliferación de géneros, como señala M. Wittig ${ }^{10}$.

Con respecto a esta primera crítica -la de que la performatividad del género reeditaría un sujeto volitivo que podría elegir su identidad de género libremente-, quisiera señalar que cuando Butler se refiere a «la elección» en el texto que cita López Pardina, esta elección nos remite a la noción de proyecto que utiliza Simone de Beauvoir, en su impronta existencialista. Al respecto, mi entender es que más bien lo que apunta Butler es que justamente esta idea de «elección» limitaría el planteo de Beauvoir si con ella se repusiera al sujeto cartesiano universal, signado por el dualismo. Es a partir de aquí que Butler recupera la noción existencialista de situación y, más particularmente, la idea de que no hay tal separación entre conciencia y cuerpo a la que apunta la misma Beauvoir. Justamente, porque el cuerpo no puede separarse de su inscripción en la conciencia (y como veremos más adelante, también y particularmente en el inconsciente), es que su materialidad no puede escindirse de su significado cultural, y por tanto no podría plantearse un sujeto descorporeizado previo al género, que elegiría su posición genérica, sino más bien un sujeto corporal que deviene tal bajo la condición de su obligatoria inserción en el orden del género.

9. LóPez PARDina, Teresa. «Prólogo a la edición española» de El segundo sexo. En S. Beauvoir, Op. Cit., pp. 7-34.

10. Ibíd., p. 27.

Feminismo/s 15, junio 2010, pp. 119-135 
Es de cara a esta concepción claramente foucaultiana de la subjetivación que, en contraposición con esta primer crítica, también se ha cuestionado la perspectiva de la performatividad por no brindar un fundamento trascendental -o dicho de otro modo, un universal fundacional- para la acción política. Inversamente a la crítica que acabamos de ver, en este caso se impugnaría el determinismo de esta concepción de la subjetivación generizada, ya que, desde esta óptica, en la medida en que se concibe el sujeto del género como un efecto de poder, no habría nada en el sujeto que pudiese excederlo. Si la resistencia al poder es a la vez inmanente al poder, ¿cómo pensar la libertad?, éste es el reclamo que se le ha hecho al pensamiento de Foucault y, consecuentemente, al planteamiento butleriano se le ha criticado lo mismo también.

Si bien estas dos líneas de crítica se encuentran en franca contraposición, lo interesante del caso es que ambas comparten la desconfianza frente al supuesto constructivismo extremo de la teoría de la performatividad de Butler. En un caso poniendo el acento en el individuo, en el otro en la sociedad, ambas críticas presuponen que Butler es una constructivista radical, y desconfían de esta posición. Es cierto que, en efecto, la perspectiva de la performatividad es heredera de las teorías del discurso y aún de la filosofía del lenguaje y que si el género es una actuación, esta actuación tiene sentido en tanto se la entiende discursivamente. Pero sin embargo, si bien las teorías del discurso han tenido una fuerte impronta en su pensamiento, el constructivismo de Butler, si es que puede pensárselo como tal, no es el de un constructivismo sociológico feliz a partir del cual el sujeto alegremente sería capaz de ir introyectando positivamente las normas sociales.

Volveré a esto en un momento, pero antes me gustaría señalar que tal vez no haya momento más constructivista que el de Beauvoir misma. Veamos nuevamente la cita con la que comenzara este trabajo. Allí Beauvoir afirmaba que «no se puede considerar a la mujer como un organismo sexuado: entre las circunstancias biológicas, sólo tienen importancia las que adoptan un valor concreto en la acción ${ }^{11}$. ¿Cómo leer este enunciado? Cuando Beauvoir comienza destruyendo los supuestos biológicos que harían a lo propio de lo femenino comienza precisamente desmontando la centralidad sexuada de la reproducción. Y muestra en ese primer capítulo, precisamente, que los datos de la biología no nos aportan ninguna información para dar con la respuesta a la pregunta del millón: ¿qué es una mujer?

Leída de este modo, en esta primera cita se deja intuir algo que Butler se encargará de radicalizar: esto es, que no hay acceso directo a un cuerpo mudo.

11. Beauvoir, Simone de. Op. Cit., p. 115.

Feminismo/s 15, junio 2010, pp. 119-135 
Ciertamente, es el cuerpo de Beauvoir el que se nos da ya como el cuerpo vivido, y por tanto ese lugar desde el que partimos y al que llegamos; nuestro cuerpo como nuestra situación, está sujeto, ya en Beauvoir, a la deriva del poder y del orden de la significación. Pero el hecho de que leamos a Beauvoir como una constructivista plena, no nos exime de revisar el constructivismo radical de Butler.

En este sentido, y volviendo al punto anterior, considero válido remarcar que el sujeto de Butler no es simplemente un sujeto sociológico que incorpora un mundo social con el cual luego habrá de negociar, sino que se trata de un sujeto que está signado por la dimensión de la fantasía y el imaginario, sin los cuales no se entienden el deseo ni la identificación; así como por la negatividad y la pérdida. ¿Cómo entender la constitución melancólica del género, si no? La impronta psicoanalítica es central al planteamiento de la subjetividad generizada de Butler y, creo, es precisamente este componente el que la aleja de los planteamientos constructivistas al uso.

En este sentido, cabe remarcar que la interpretación del psicoanálisis que hace Beauvoir, quien reconoce preferir en última instancia a Adler antes que a Freud, tiende a ver la aportación del psicoanálisis como una posible -aunque incompleta- comprensión del proceso mediante el cual el «bebé-animalhumano» se convertiría en una individualidad social exclusivamente como un proceso de socialización, esto es, como un proceso de incorporación de valores sociales, lo cual reforzaría su constructivismo. En esta lectura, en cierto modo Beauvoir tiende a sociologizar al psicoanálisis de tal modo que parecería reducirlo a una suerte de psicología social del yo. Mientras tanto, y a diferencia de esta suerte de sociologización constructivista de Beauvoir, verdaderamente radical para la época, en Butler encontramos una seria y profunda distinción entre lo social y lo psíquico.

Ahora bien, ¿cómo entender desde Butler esta dimensión psíquica? ¿Qué toma Butler del psicoanálisis y qué deja de lado? Este resto psíquico, caracterizado como lo inconsciente, que se da como el efecto de la entrada de 'un todavía no sujeto' en el orden de la subjetivación, no es un interior psíquico natural, sino uno que se conforma a partir de las prohibiciones que sanciona un orden social. De este modo, el trauma no recuperable -esa pérdida constitutiva- que vuelve al sujeto opaco y desconocido para sí mismo es el efecto de las normas culturales que a un mismo tiempo condicionan y habilitan la producción de una subjetividad. En efecto, como en Beauvoir, en Butler también la conformación del yo (y también de su inconsciente) forman parte de un proceso social. Pero a diferencia de Beauvoir, esto genera una dimensión 
-la psíquica - cuya dinámica no puede homologarse a la lógica de la mera socialización, visualizada como un proceso de introyección o incorporación.

\section{Del cuerpo freudiano al cuerpo vivido. Últimas reflexiones a modo de conclusión}

El cuerpo con sus deseos y sus identificaciones están en el centro de esta cuestión que Butler plantea en Mecanismos psíquicos del poder. Allí, la autora se pregunta cómo es posible concebir la resistencia al poder. Y se pregunta cómo es el cuerpo que concibe Foucault para poder comprenderlo como aquello que es el efecto del disciplinamiento, pero a la vez la fuente de la resistencia al mismo. Paralelamente, entonces, se pregunta cómo ha de ser concebido el inconciente, si éste es el resto que se resiste a la domesticación de las normas sociales. Su conclusión es que las restricciones constitutivas que hacen a la posibilidad de la subjetivación así como a su resistencia no provienen ni de los dictámenes de un cuerpo-cosa ni de una ley simbólica anterior a la cultura. Muy por el contrario, éstas no están por fuera de lo social ya que son las normas las que producen ese exceso, gracias al cual, de hecho, asumimos unas sexualidades (y unas identificaciones) que siempre nos exceden y que en el fondo desconocemos o, por lo menos, nunca conocemos del todo.

Sostiene Butler, siguiendo en esto a Freud, que «el 'yo' es la proyección de una superficie corpórea»-«El Yo es, ante todo, un ser corpóreo y no sólo un ser superficial, sino incluso la proyección de una superficie», sentencia la célebre formulación de Freud-. Esta caracterización que la autora toma del ensayo «El yo y el ello» ${ }^{12}$ es de suma relevancia para comprender la distinción entre lo psíquico y lo social. Allí se pone de manifiesto que la dimensión psíquica se dará en, por, a través, de la instancia de la corporalidad. Líneas antes de escribir su famosa frase, el autor aclara: «El propio cuerpo, y sobre todo, la superficie del mismo, es un lugar del cual pueden partir simultáneamente, percepciones externas e internas» ${ }^{13}$. Es así que este cuerpo que es un cuerpo vivido es la misma imagen del aparato psíquico, que antes que una interioridad, funciona como una especie de membrana o filtro por el que pasan y en definitiva no pueden separarse el mundo externo del interno. Un poco antes, precisamente a los fines de criticar la tópica interior/inalcanzable exterior/ evidente, que da lugar a la segunda tópica, Freud afirma:

12. FreUd, Sigmund. «El yo y el Ello». En S. Freud, Obras Completas. Tomo III. Madrid Biblioteca Nueva, 1973 [1923], pp. 2701-2728.

13. Freud, Sigmund. Op. Cit., p. 2718. 
Todas las percepciones procedentes del exterior (percepciones sensoriales) y aquellas otras, procedentes del interior, a las que damos el nombre de sensaciones y sentimientos, son conscientes. Pero, iy aquellos procesos internos que podemos reunir, aunque sin gran exactitud, bajo el concepto de procesos mentales, y que se desarrollan en el interior del aparato, como desplazamientos de energía psíquica a lo largo del camino que conduce a la acción; llegan acaso a la superficie en la que nace la conciencia? ¿O es la conciencia la que llega hasta ellos? Es esta una de las dificultades que surgen cuando nos decidimos a utilizar la representación espacial, tópica, de la vida anímica. Ambas posibilidades son igualmente inconcebibles y habrán, por lo tanto, de dejar paso a una tercera ${ }^{14}$.

Si retomamos el carácter social de esta configuración, esta idea de que el yo es la proyección de una superficie corpórea implica también que las normas se alojan en el cuerpo, o aun más, que las normas, en tanto cauces de vida y en tanto espacios de negociación, son en el cuerpo mismo (así como el cuerpo de un modo u otro es en la norma). Al decir esto, lo que se señala entonces es que no hay una norma por un lado y por el otro un cuerpo que fuera a incorporarla: normatividad social y corporeización son un nudo -o un quiasmo, como lo plantearía, aunque en otra clave, Merleau-Ponty- ${ }^{15}$. Con respecto al cuerpo, y muy en esta línea, Beauvoir afirma:

Se dirá que, desde la perspectiva que adopto -la de Heidegger, Sartre, Merleau-Ponty-, si el cuerpo es una cosa, es una situación: es nuestra forma de aprehender el mundo y el esbozo de nuestros proyectos ${ }^{16}$.

Y más adelante, precisamente cuando señala la inmensa contribución del psicoanálisis, agrega:

[L] o que existe concretamente no es el cuerpo-objeto descrito por los científicos sino el cuerpo vivido por el sujeto ${ }^{17}$.

Al hilo de estas últimas citas de Beauvoir, quizás se podría pensar que tal vez haya mucho del cuerpo Beauvoiriano habitando en la letra de Butler. Al fin de

14. Ibíd., p. 2716.

15. En línea con la crítica a su constructivismo, también se le ha cuestionado a Butler que convirtiendo todo registro de lo corporal en discurso, el cuerpo como materia, experiencia o vida, era dejado de lado en pos de la significación. Sin embargo, la obra de Butler da cuenta de una continuada reflexión sobre la corporalidad, desde la reformulación de la concepción naturalista del «sexo» y poniendo a discusión el binomio sexo/ género, en sus primeros escritos, hasta la pregunta por «la vida del animal-humano», la cual la lleva a pensar en la vulnerabilidad y la desposesión como su condición de existencia en sus últimas obras. Sobre la cuestión de la corporalidad en Butler, véase Sabsay, Leticia. «Tras la firma de Judith Butler. Una introducción posible a los ecos de su escritura». AIBR Revista de Antropología Iberoamericana 4:3 (2009), pp. 311-320.

16. BEauvoir, Simone de. Op. Cit., p. 97.

17. Ibíd., p. 101.

Feminismo/s 15, junio 2010, pp. 119-135 
cuentas, de algún modo, es partiendo del cuerpo que el texto de Beauvoir nos habla de las formas de negociación de este género que devenimos. Y Butler, en definitiva, también ha dedicado gran parte de su obra a pensar en cómo se negocia (este binarismo de) la normativa genérica. En línea con Beauvoir, Butler también nos ha dicho que:

[E] l género es una forma contemporánea de organizar las normas culturales pasadas y futuras, una forma de situarse en y a través de esas normas, un estilo activo de vivir el propio cuerpo en el mundo ${ }^{18}$.

Si en Beauvoir de lo que se trata es de acceder a la trascendencia como sujeto-humano libre, lo que implicaría no tanto convertirse a lo masculino y terminar con las mujeres, como transformar a «la mujer», cuestionando su inmanencia, en Butler tampoco se tratará de trascender el género, pero sí de redistribuirlo.

Si en términos ético-políticos, estos dos proyectos implican desde el existencialismo de Beauvoir, buscar condiciones que sean lo menos limitantes posibles para la realización de la propia libertad de cada uno/a, y desde Butler distribuir lo más justamente posible la condiciones que hacen a la posibilidad de acceder a la vida-humana -en palabras de la autora: «maximizar el potencial de vidas vivibles»-, quizás resulte que este acto de arrojo que supone concebir al género de forma performativa sea mucho más fiel al proyecto de Beauvoir que lo que una podría esperar.

\section{Referencias bibliográficas}

BEAUvoir, Simone de. El segundo sexo. Madrid, Cátedra, 2005 [1949].

BUTLER, Judith. «Variaciones sobre sexo y género: Beauvoir, Wittig y Foucault».

En S. Benhabib y D. Cornell (eds.). Teoría feminista/Teoría crítica. Valencia, Alfons el Magnànim, 1989, pp. 193-211.

- El género en disputa. El feminismo y la subversión de la identidad. México, Paidós/PUEG, 2001 [1990].

- Cuerpos que importan. Sobre los límites discursivos del «sexo». Buenos Aires, Paidós SAICF, 2002 [1993].

- Mecanismos psíquicos del poder. Madrid, Cátedra, 2002 [1997].

- Deshacer el género. Barcelona, Paidós, 2006 [2004].

FreUd, Sigmund. «El yo y el ello». En S. Freud, Obras Completas Tomo III, Madrid, Biblioteca Nueva, 1973 [1923] pp. 2701-2728.

LóPez PARDina, Teresa. «Prólogo a la edición española» de El segundo sexo. En S. Beauvoir, Op. Cit., pp. 7-34.

18. ButLer, Judith. Op. Cit., p. 197. 
Merleau-Ponty, Maurice. «EL quiasmo». En M. Merleau-Ponty, Lo visible y lo invisible. Barcelona, Seix-Barral, 1970 [1964], pp. 163-192.

SABSAY, Leticia. Los dilemas del antiesencialismo en la teoría feminista contemporánea: una reflexión en torno a Judith Butler. Almería, Instituto de Estudios Almerienses/Diputación de Almería, 2007.

- «Tras la firma de Judith Butler. Una introducción posible a los ecos de su escritura». AIBR Revista de Antropología Iberoamericana, 4:3 (2009), pp. 311-320.

ScotT, Joan W. «El género, una categoría útil para el análisis histórico». En C. Stimpson, y M. Navarro (eds.), Sexualidad, género y roles sexuales. Buenos Aires, FCE, 1999. 